\title{
Quality of Life (QoL) Assessment in the Patients Operated with Either Laparoscopic or an Open Aortobifemoral Bypass for Aortoiliac Occlusive Disease (AIOD): 2 Years Results of a Randomized Controlled Trial
}

\author{
Mehdi Sahba $\mathbb{D}^{1,2}$, Anne Helene Krog (D)', Erik Mulder Pettersen ${ }^{3}$, Torbjørn Wisløff ${ }^{4}$, \\ Jon Otto Sundhagen $\mathbb{D}^{5}$, Syed Sajid Hussain Kazmi $\mathbb{D}^{2,5}$
}

'Department of Vascular Surgery, Østfold Central Hospital, Kalnes, Norway; ${ }^{2}$ Institute of Clinical Medicine, Faculty of Medicine, University of Oslo, Oslo, Norway; ${ }^{3}$ Department of Vascular Surgery, Sørlandet Hospital HF, Kristiansand, Norway; ${ }^{4}$ Health Services Research Unit, Akershus University Hospital, Lørenskog, Norway; ${ }^{5}$ Department of Vascular Surgery, Division of Cardiovascular and Pulmonary Diseases, Oslo University Hospital, Ullevål, Oslo, Norway

Correspondence: Syed Sajid Hussain Kazmi, Tel +47 92468309, Email sshkazmi@gmail.com

Background: QoL assessment within surgical treatment is seldom investigated and sparsely reported in the medical literature. This study aimed to compare QoL in a randomized fashion in the patients treated with either a laparoscopic aortobifemoral bypass (LABFB) or an open aortobifemoral bypass (OABFB) for the treatment of AIOD.

Patients and Methods: Seventy-one consecutive patients with AIOD, Trans-Atlantic Inter-Society Consensus II Type D lesions (TASC II, Type D) were randomized to LABFB or OABFB. Thirty-five patients in the LABFB and thirty-six in the OABFB groups were compared for the changes in the QoL, with the short-form health survey (SF-36), EuroQol 5 dimensions (EQ-5D), and EQ-5D visual analog scale (VAS) preoperatively, and postoperatively at 1, 3, 6, 12 and 24 months. Mann-Whitney $U$-Test and Wilcoxon sign-rank test were used for group comparison. Mixed model analysis was performed to examine the effect of different variables on the QoL.

Results: In the patients treated with LABFB, physical component score (PCS) and mental component score (MCS) in SF-36 were significantly higher than OABFB, at 1 and 3 months postoperatively. PCS was also significantly higher in the LABFB group than OABFB at 24 months postoperatively. The preoperative QoL scores for both the laparoscopy and the open group were significantly lower than the age-matched general Norwegian population. EQ-5D median scores were significantly higher in the LABFB at all postoperative follow-up time points up to 12 months. The patients in the LABFB group also had a statistically significant increase in EQ-5D VAS compared to OABFB, at 1 and 12 months postoperatively ( $\mathrm{p}=0.005$, and $\mathrm{p}=0.037$, respectively).

Conclusion: QoL seems better in patients treated with LABFB than OABFB, particularly during the early months after surgery.

Keywords: health-related quality of life, EQ-5D, SF-36, laparoscopy, aortobifemoral bypass, PROMs

\section{Background}

Most of the patients with AIOD, even with advanced TASC II type D lesions, are primarily treated with endovascular procedures. ${ }^{1,2}$ Although the mid- and long-term patency of the endovascular procedures and the aortobifemoral bypass are comparable, the endovascular treatment option is preferred due to its minimally invasive nature and significantly lower peri-procedural morbidity. ${ }^{3,4}$ Especially in the elderly patients and those with a high risk of operative complications due to co-morbidities, endovascular treatment is the preferred treatment option. However, in case of unsuccessful endovascular treatment, atherosclerotic lesions not amenable for an endovascular procedure, or in young patients with acceptable risk of perioperative complications, open aortobifemoral bypass is the preferred treatment option. ${ }^{5}$ 
Laparoscopic aortobifemoral bypass surgery for treating patients with advanced peripheral arterial disease (PAD) has been progressively established in dedicated centers. ${ }^{6-8}$ Published literature on PAD often is focused on traditional outcomes like graft patency, maximum walking distance, mortality, and morbidity. ${ }^{4}$ New treatment modalities should not only be evaluated in terms of patency, complication, and long-term results but also QoL assessments. ${ }^{9-12}$ Patients with PAD have been shown to have a reduced health-related quality of life (HRQoL). ${ }^{13,14}$ The literature on QoL for patients with advanced PAD is sparse, and especially, long-time follow-up studies assessing QoL and randomized controlled trials are lacking, especially in the patients with AIOD operated with aortobifemoral bypass. ${ }^{15}$

Patient-reported outcome measurements (PROMs) are essential tools in evaluating outcomes of different treatment methods in patients with PAD. ${ }^{16}$ Additionally, these tools provide essential information to the health providers and the taxpayers for assessing health services. ${ }^{11,16}$ From the patient's perspective, changes in the physical domains of a QoL tool after a treatment serve as a direct measure of the treatment effect. ${ }^{14,17}$

This sub-study aimed to evaluate the short and mid-term impact of LABFB and OABFB surgery on the QoL of the patients with TASC II type D lesions with generic questionnaire instruments, SF-36 and EQ-5D. EQ-5D Visual Analogue Scale (VAS) was used to register the patients' perception of their health at each measuring time point.

\section{Patients and Methods}

\section{Design}

This study is a sub-study of an ongoing prospective randomized multicenter study, the Norwegian Laparoscopic Aortic Surgery Trial (NLAST). The primary objective of the NLAST trial is postoperative systemic and local complications. One of the secondary objectives was to assess QoL using PROMs. Since QoL was a sub-study, no power analysis was conducted. Between March 2013 and March 2019, seventy-one consecutive patients with AIOD, TASC II type D lesion, were randomized to either LABFB or OABFB (Figure 1). Inclusion and exclusion criteria are described in Table 1. We used two generic PROMs tools, SF-36 version 2 and EQ-5D. ${ }^{19,20}$

The SF-36 includes eight domains, with individual domain scores and two summary scores: a physical component score (PCS) and a mental component score (MCS). The summary scores are comprised of 4 domains in each component score. Each of the eight individual domains scores from 0 to 100; a higher score indicates better QoL.

In addition, all patients had to provide his/her perception about their current health status with the help of EQ-5D VAS. They could choose a value from a scale ranging from 0 to 100, where 100 depicted the best possible general health status.

The HRQoL questionnaires were answered by the participating patients in the study preoperatively (baseline) and at 1, 3, 6, 12, and 24 months postoperatively. QualityMetric Health Outcome Scoring Software 5.0 program was used to register SF-36 data. This software uses US standard norm from 1998 for scoring of the values, and these summary component scores are validated to be used across European countries. ${ }^{19,21}$

\section{Statistics}

Statistical Package for Social Science, version 25 (SPSS, IBM, ARMONK, NY, USA) was used for statistical analysis. Baseline characteristics were compared by using the Independent Samples $t$-test. Median and interquartile range (IQR) were calculated for both groups. In addition to the separate analysis of each SF-36 domain, PCS and MCS were analyzed. Mean baseline scores were compared with the age-matched Norwegian population scores. Mann-Whitney $U$-Test was used to analyze the changes at each measuring time-point between the two groups. The changes over time in SF-36, EQ-5D, and VAS compared to baseline were analyzed by Wilcoxon Signed test. Mixed model analysis was performed to find the effect of different variables on PCS, MCS, and EQ-5D scores. The level of statistical significance was set at $5 \%(\mathrm{p}<0.05)$.

\section{Participants}

Patients from 3 vascular surgery units in the southeastern region of Norway participated in this study. 


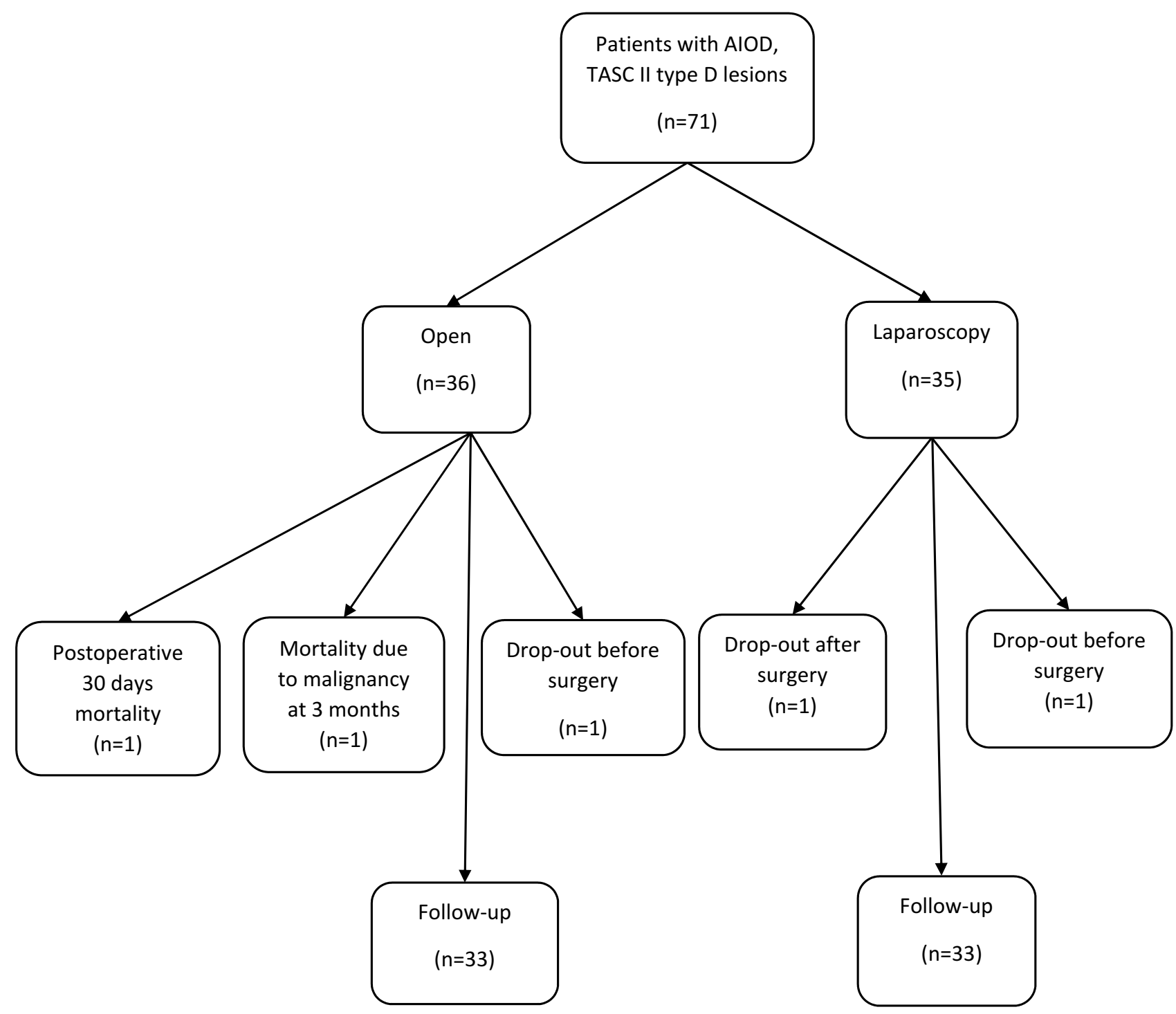

Figure I Flow chart of patients with the aortoiliac occlusive disease, with Trans-Atlantic Inter-Society Consensus II Type D lesions, randomized to either laparoscopic or aortobifemoral bypass, and followed-up for changes in the quality of life. ${ }^{2}$

\section{Ethical Statement}

The Regional Committee for Medical Health Research Ethics (REC, region south-east of Norway, registration number 2012/1367) approved the study. The NLAST trial was also registered at http://www.clinicaltrials.gov, with the registration number NCT01793662. The study was conducted per the Declaration of Helsinki. All patients gave informed, written consent prior to the study commencement.

\section{Results}

Baseline characteristics did not differ in the laparoscopic and open surgery groups. Table 2 summarizes the baseline characteristics. ${ }^{22}$ Two patients (2.9\%), one in each group, did not receive surgical treatment after randomization and were registered as drop-outs. Another (1.4\%) in the LABFB group did not follow the postoperative control program and was deemed lost to follow-up. One patient (1.4\%) died two days after OABFB.

The preoperative questionnaire response rate was $97 \%$ in the LABFB and $94.4 \%$ in the OABFB. The postoperative response rates for laparoscopy and open group were $91.4 \%$ versus $91.7 \%$ at one month, $88.6 \%$ versus $88.9 \%$ at 3 months, $94.3 \%$ versus $88.9 \%$ at 6 months, $94.3 \%$ versus $83.3 \%$ at 12 months and $91.4 \%$ versus $83.3 \%$ at 24 months, respectively. 
Table I Inclusion and Exclusion Criteria for Patients with the Aortoiliac Occlusive Disease (AIOD), Trans-Atlantic Inter-Society Consensus II (TASC II) Type D Lesions, Treated with Either Open or Laparoscopic Aortobifemoral Bypass. ${ }^{2}$

\begin{tabular}{|l|l|}
\hline Inclusion Criteria & \multicolumn{1}{c|}{ Exclusion Criteria } \\
\hline Patient with AIOD, TASC II type D and symptoms in form of: & - Fit for endovascular procedure \\
- Intermittent claudication, with walking distance $<200$ meters and/or & - COPD stage IV, GOLD classification ${ }^{18}$ \\
- Chronic limb threatening ischemia with rest pain or ischemia ulcers & - Symptomatic coronary heart disease \\
with duration of symptoms $>2$ weeks & - Chronic heart failure, EF (Ejection fraction) $<40 \%$ \\
& - Active cancer disease \\
& - Hostile abdomen, previous multiple open major abdominal \\
& surgeries \\
& - Abdominal aortic aneurysm (AAA) $\geq 3.0 \mathrm{~cm}$ \\
& - Acute limb threatening ischemia. Duration of symptoms $\leq 2$ weeks \\
\hline
\end{tabular}

Abbreviations: TASC, Trans-Atlantic Inter-Society Consensus; COPD, chronic obstructive pulmonary disease; GOLD, Global Initiative for Chronic Obstructive Lung Disease.

Table 2 Baseline Characteristics of Patients Included in the Study, Treated with Either a Laparoscopic or an Open Aortobifemoral Bypass to Treat Aortoiliac Occlusive Disease (AIOD), with Trans-Atlantic Inter-Society Consensus II Type D Lesions. ${ }^{2}$

\begin{tabular}{|l|l|l|l|}
\hline Baseline Characteristics & LABFB (N=35) & OABFB (N=36) & p-value \\
\hline Age in years, mean (SD) & $63(7)$ & $64.1(7.1)$ & 0.49 \\
Male gender n (\%) & $16(45.7)$ & $17(47.2)$ & 0.72 \\
Current smoker n (\%) & $16(45.7)$ & $10(27.7)$ & 0.23 \\
Hypertension n (\%) & $24(68.5)$ & $26(72.2)$ & 0.55 \\
Diabetes Mellitus n (\%) & $2(5.7)$ & $4(11.1)$ & 0.42 \\
CHD n (\%) & $6(17.1)$ & $8(22.2)$ & 0.6 \\
COPD n (\%) & $8(22.8)$ & $7(19.4)$ & 0.73 \\
Fontaine classification n (\%) & & & \\
Class 2b & $27(77.1)$ & $30(83)$ & \\
Class 3 & $6(17.1)$ & $6(16.7)$ & \\
Class 4 & $2(2.7)$ & 0 & 0.67 \\
Cerebrovascular disease n (\%) & $2(5.7)$ & $3(8)$ & 0.74 \\
Previous PTA n (\%) & $14(40)$ & $12(33)$ & 0.97 \\
Previous vascular surgery n (\%) & $3(8.5)$ & $3(8)$ & \\
\hline
\end{tabular}

Notes: Independent samples $t$-test; Fountain classification; a classification of symptoms in peripheral arterial disease ${ }^{22}$.

Abbreviations: NLAST, Norwegian laparoscopic aortic surgery; CHD, coronary heart disease; COPD, chronic obstructive pulmonary disease; PTA, percutaneous transluminal angioplasty.

The results of comparing the SF 36 domain scores and the PCS and MCS, between LABFB and OABFB at each followup time-point, are given in Table 3 and illustrated in Figure 2. At 1 month time-point, the LABFB had a significantly higher increase in seven of the eight SF-36 domains' scores (PF $p=0.006, \mathrm{BP} p=0.027, \mathrm{GH} p=0.018, \mathrm{VT} p=0.029, \mathrm{SF} p=0.044$, $\mathrm{RE} p=0.027, \mathrm{MH} \mathrm{p}=0.016$ ) as compared with the OABFB. The summary scores, PCS and MCS, were also significantly higher $(p=0.028$ and $p=0.023)$ in the LABFB group than the OABFB group.

At the 3-month time-point, the LABFB group, as compared with the OABFB group, had a significantly higher increase in four of the eight SF-36 domains' scores (RP $p=0.037, \mathrm{BP} p=0.049, \mathrm{VT} p=0.012$, SF $p=0.006$ ), as well as both PCS $(\mathrm{p}=0.043)$ and MCS $(\mathrm{p}=0.048)$.

At the 6-month time-point, the LABFB group, compared with the OABFB, had a significantly higher increase in four of the eight SF-36 domains' scores (RP $p=0.038$, BP $p=0.041$, SF $p=0.022$, RE $p=0.016$ ), but MCS and PCS were not significantly different between the groups.

At the 12-month time-point, two SF-36 domains' scores ( $\mathrm{SF} p=0.022$ and PF $\mathrm{p}=0.011$ ) were still significantly higher in favor of the LABFB group than the OABFB, but the groups did not differ significantly in terms of PCS and MCS. 
Table 3 Longitudinal Comparison of SF-36 Domain Scores at Different Follow-Up Time-Points Between the Laparoscopic and Open Aortobifemoral Bypass Patients with AIOD, TASC II Type D Lesions. ${ }^{2}$

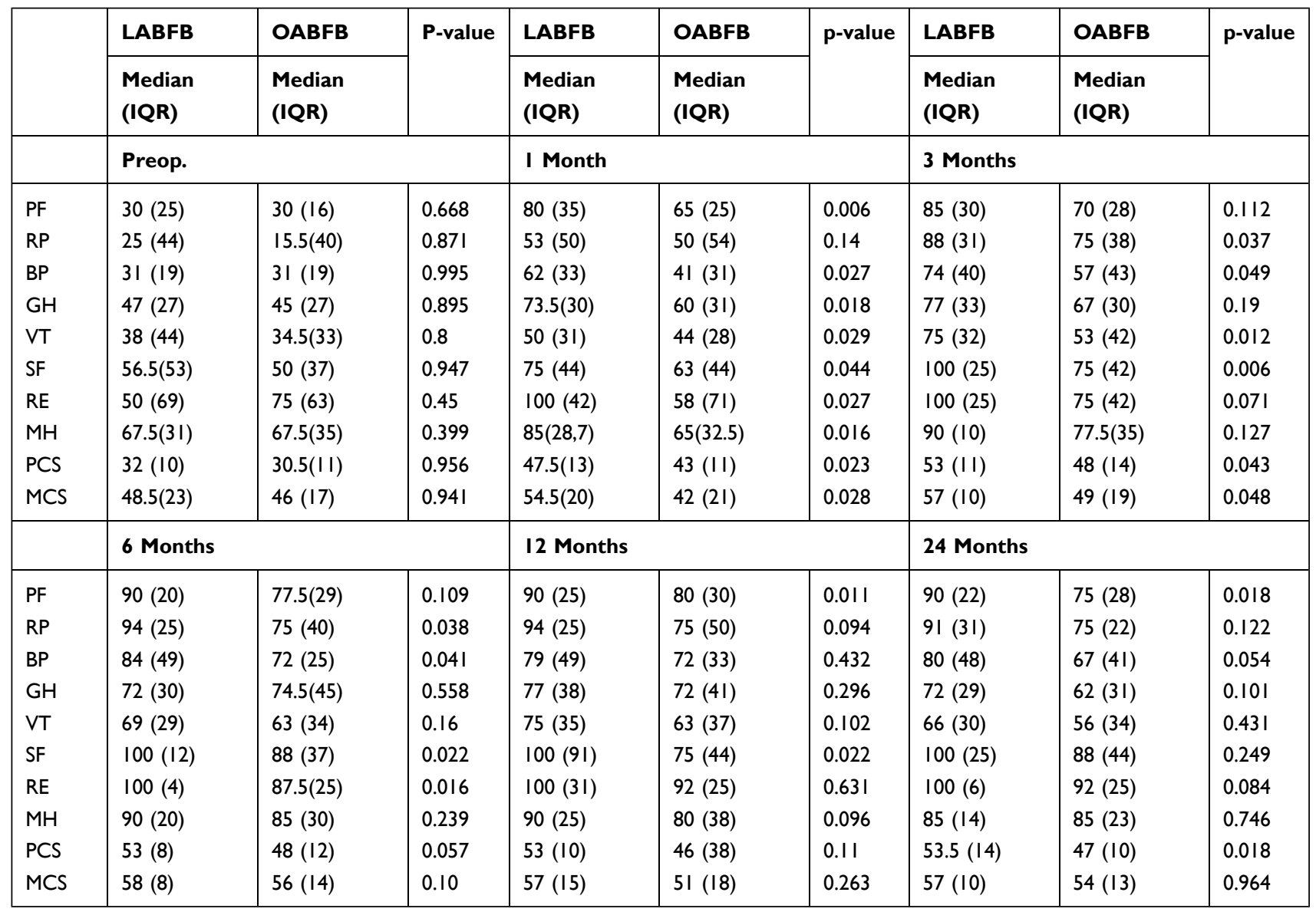

Note: Statistics Mann-Whitney U-test.

Abbreviations: PF, physical functioning; RP, role physical; BP, bodily pain; GH, general health; VT, vitality; SF, social functioning; RE, role emotional; MH, mental health; PCS, physical component score; MCS, mental component score; LABFB, laparoscopic aortobifemoral bypass; OABFB, open aortobifemoral bypass; IQR, Interquartile range; AIOD, Aortoiliac occlusive disease; TASC, Trans-Atlantic Inter-Society Consensus.

At the 24-month time-point, PF $(p=0.018)$ and PCS $(p=0.018)$ were still significantly higher in the LABFB group than the OABFB.

The mixed model regression analysis results showed that PCS scored significantly better in the LABFB group than OABFB. Operation time affected significantly negatively on the PCS. Gender, age and reoperations, and the length of hospital stays did not significantly affect the PCS in both groups.

The effect of operation type on MCS favored LABFB; however, it had a borderline statistical significance $p=0.05$. In both groups, postoperative MCS was not significantly affected by gender, age, operation time, reoperations, and length of hospital stay within 30 days postoperatively. The results of the mixed model analysis are presented in Table 4 .

The comparison of SF-36 median scores in both patient groups with the age-matched Norwegian population showed significantly lower preoperative QoL scores in the study population. ${ }^{23}$ All SF-36 domains in LABFB were improved at 1-month follow-up and were even better after 3-month as compared with the general norms. This improvement in the QoL domains was consistent throughout the follow-up period. In the OABFB group, all SF-36 domain scores increased postoperatively at all follow-up time-points, except for $\mathrm{RE}$ and $\mathrm{MH}$ at 1-month time-point. Figure 3 illustrates the changes in SF-36 QoL domains in both treatment groups compared with the preoperative scores.

The EQ-5D median scores for each time-point showed significantly better postoperative scores until 12 months in the LABFB group than the OABFB group. The comparison of the EQ-5D scores in both treatment groups at each time point is given in Table 5 . 


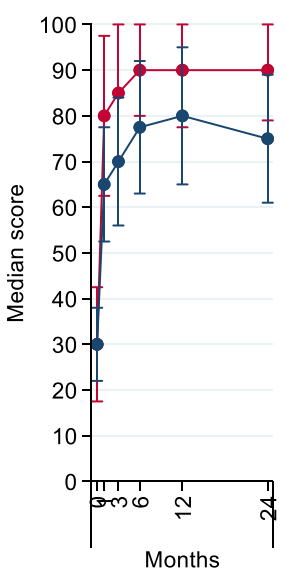

PF

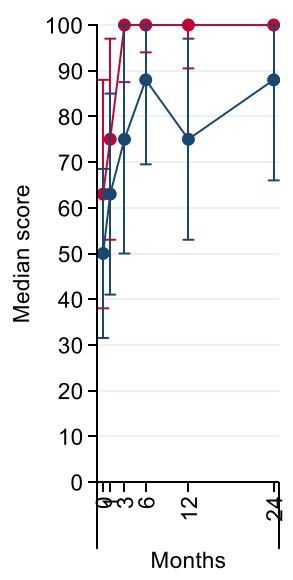

SF

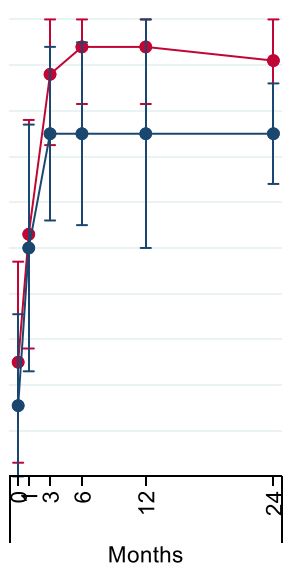

RP
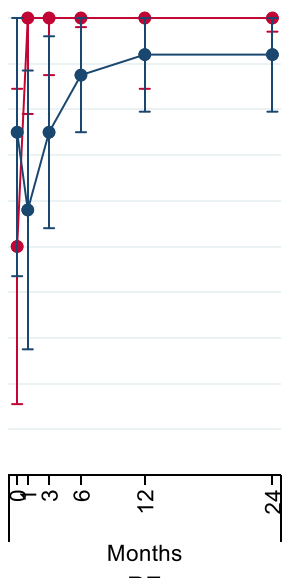

RE
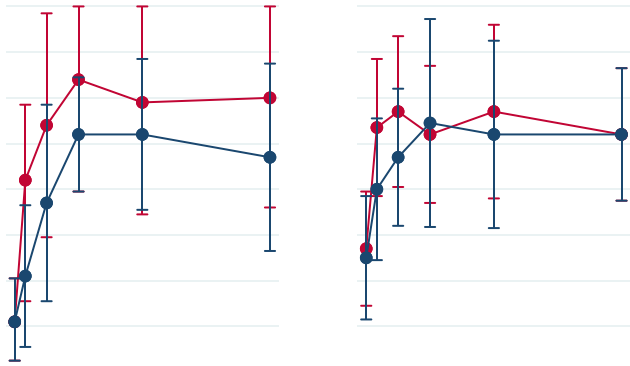

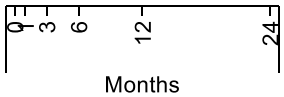

BP

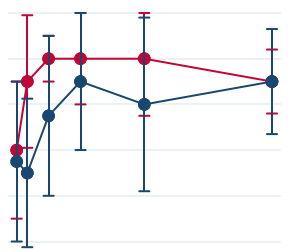

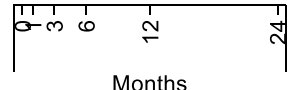

$\mathrm{GH}$

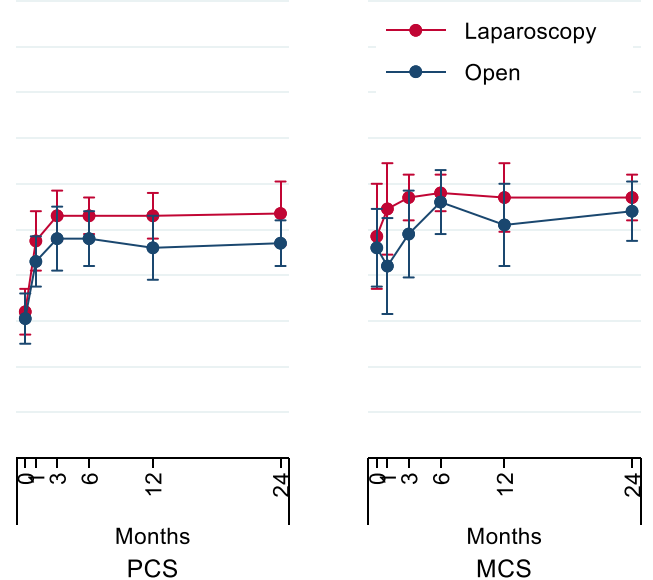

Figure 2 SF-36 individual and summary scores at different time-points for 71 patients randomized to either laparoscopic or open aortobifemoral bypass to treat advanced aortoiliac occlusive disease, TASC II Type D lesions. ${ }^{2}$ The vertical bars represent interquartile range.

Abbreviations: PF, physical functioning; RP, role physical; BP, bodily pain; GH, general health; VT, vitality; SF, social functioning; RE, role emotional; MH, mental health; PCS, physical component score; MCS, mental component score; TASC II, Trans-Atlantic Inter-Society Consensus II.

In a mixed model regression analysis, only operation type significantly affected EQ-5D scores, favoring LABFB, $\mathrm{p}<$ 0.001. Age and gender had no significant effect on EQ-5D scores.

Postoperative EQ-5D scores showed significant improvement at all time points in both treatment groups as compared with the preoperative scores $(\mathrm{p}<0.001)$ (Figure 4). The comparison of EQ-5D VAS scores at different time points between the treatment groups showed significantly higher scores at 1 and 12 months postoperatively in the LABFB group (Table 6).

\section{Discussion}

To the best of our knowledge, this is the first randomized study that investigates and compares the impact of LABFB and OABFB on the short and mid-term QoL of patients with AIOD, TASC II type D lesions. The QoL has been investigated with SF-36 and EQ-5D questionnaires for a follow-up period of 24 months. SF-36 and EQ-5D are the most frequently used QoL instruments. Both are validated for assessing QoL in PAD. ${ }^{24,25}$ SF-36 has been validated for the assessment of the QoL of the Norwegian population. ${ }^{23,26}$

Considering the duration of the study over six years, a response rate of $83.3 \%$ to $97 \%$ is relatively high. The preoperative response rate was not $100 \%$, but it could be explained by the patient's inability to fill the QoL questionnaires due to illness. The postoperative response rate above $83 \%$ at 24 months, including drop-out before surgery (2.8\%) and death $(2.8 \%)$ during follow-up, is acceptable. 
Table 4 Mixed Model Analysis of Different Variables Effects on PCS, MCS, and EQ-5D Scores in the Patients with Advanced Aortoiliac Occlusive Disease, TASC II Type D Lesions. ${ }^{2}$

\begin{tabular}{|c|c|c|c|c|c|c|}
\hline & \multirow[t]{2}{*}{ Coefficient } & \multirow[t]{2}{*}{ Std. Error } & \multirow[t]{2}{*}{$\mathbf{t}$} & \multirow[t]{2}{*}{ Sig. } & \multicolumn{2}{|c|}{$95 \% \mathrm{Cl}$} \\
\hline & & & & & Lower & Upper \\
\hline \multicolumn{7}{|l|}{ PCS } \\
\hline Intercept & 47.8 & 6.68 & 7.16 & 0.000 & 34.668 & 60.937 \\
\hline LABFB & 2.456 & 1.136 & 2.16 & 0.031 & 0.221 & 4.691 \\
\hline OABFB & 0 & & & & & \\
\hline Operation time & -0.011 & 0.0052 & -2.02 & 0.044 & -0.021 & 0.000 \\
\hline Length of hospital stay & -0.112 & 0.113 & -0.99 & 0.324 & -0.335 & 0.111 \\
\hline Female & 1.121 & 0.99 & 1.132 & 0.258 & -0.827 & 3.069 \\
\hline Male & 0 & & & & & \\
\hline Reoperation (no) & -1.343 & 2.20 & -0.60 & 0.543 & -5.682 & 2.997 \\
\hline Reoperation (yes) & 0 & & & & & \\
\hline Time 12 months postop. & 1.090 & 1.62 & 0.672 & 0.502 & -2.10 & 4.281 \\
\hline \multicolumn{7}{|l|}{ MCS } \\
\hline Intercept & 51.08 & 6.39 & 7.993 & 0.000 & 38.51 & 63.651 \\
\hline LABFB & 2.455 & 1.298 & 1.899 & 0.050 & -0.088 & 4.998 \\
\hline OABFB & 0 & & & & & \\
\hline Operation time & 0.007 & 0.006 & 1.099 & 0.273 & -0.005 & 0.019 \\
\hline Length of hospital stay & -0.024 & 0.129 & -0.186 & 0.852 & -0.278 & 0.23 \\
\hline Female & 0.073 & 1.148 & 0.064 & 0.949 & -2.186 & 2.333 \\
\hline Male & 0 & & & & & \\
\hline Reoperation (no) & 1.781 & 2.536 & 0.702 & 0.483 & -3.208 & 6.77 \\
\hline Reoperation (yes) & 0 & & & & & \\
\hline Time 12 months postop. & -1.427 & 1.765 & -0.809 & 0.419 & -4.899 & 2.045 \\
\hline \multicolumn{7}{|l|}{ EQ-5D } \\
\hline Intercept & 0.906 & 0.086 & 10.488 & 0.000 & 0.736 & 1.076 \\
\hline LABFB & 0.076 & 0.0174 & 4.355 & 0.000 & 0.042 & 0.110 \\
\hline OABFB & 0 & & & & & \\
\hline Age & -0.001 & 0.001 & -0.873 & 0.383 & -0.004 & 0.002 \\
\hline Male & 0.02 & 0.017 & 1.163 & 0.246 & -0.014 & 0.054 \\
\hline Female & 0 & & & & & \\
\hline Time 12 months postop. & -0.003 & 0.0300 & -0.112 & 0.911 & -0.062 & 0.056 \\
\hline
\end{tabular}

Abbreviations: PCS, physical component score; MCS, mental component score; EQ-5D, EuroQol 5 dimensions level; TASC II, Trans-Atlantic Inter-Society Consensus II.

This study confirms that the patients with AIOD, TASC II type D lesions have significantly reduced QoL compared with the age-matched Norwegian general population. The baseline QoL scores in our study are even worse than previously reported SF-36 scores in patients with intermittent claudication, probably due to the severity of their disease. ${ }^{27}$

Postoperative SF-36 results showed that the patients treated with either technique, ie, LABFB or OABFB, achieved a statistically significant improvement in QoL, already at the first measuring time-point (1-month). This improvement in the QoL continued at three months. The effect of the operative treatment on QoL was consistent throughout the postoperative follow-up period of 24 months for both groups. At 24 months, all domains of SF-36 are close to the agematched Norwegian general population.

However, the magnitude of the improvement in QoL at different postoperative time points was more in the patients treated with LABFB than with OABFB, shown by the SF-36 summary scores and the individual domain scores. SF-36 is an excellent tool for objectively registering the changes in all physical and mental components of the QoL. ${ }^{16,28}$

Postoperative EQ-5D scores are significantly better in the LABFB than OABFB at all time points until 12 months. However, at the 24-month the difference between the two groups was no longer significantly different. A persistent improvement in the QoL was observed throughout the follow-up time of this study for both operative procedures, with 


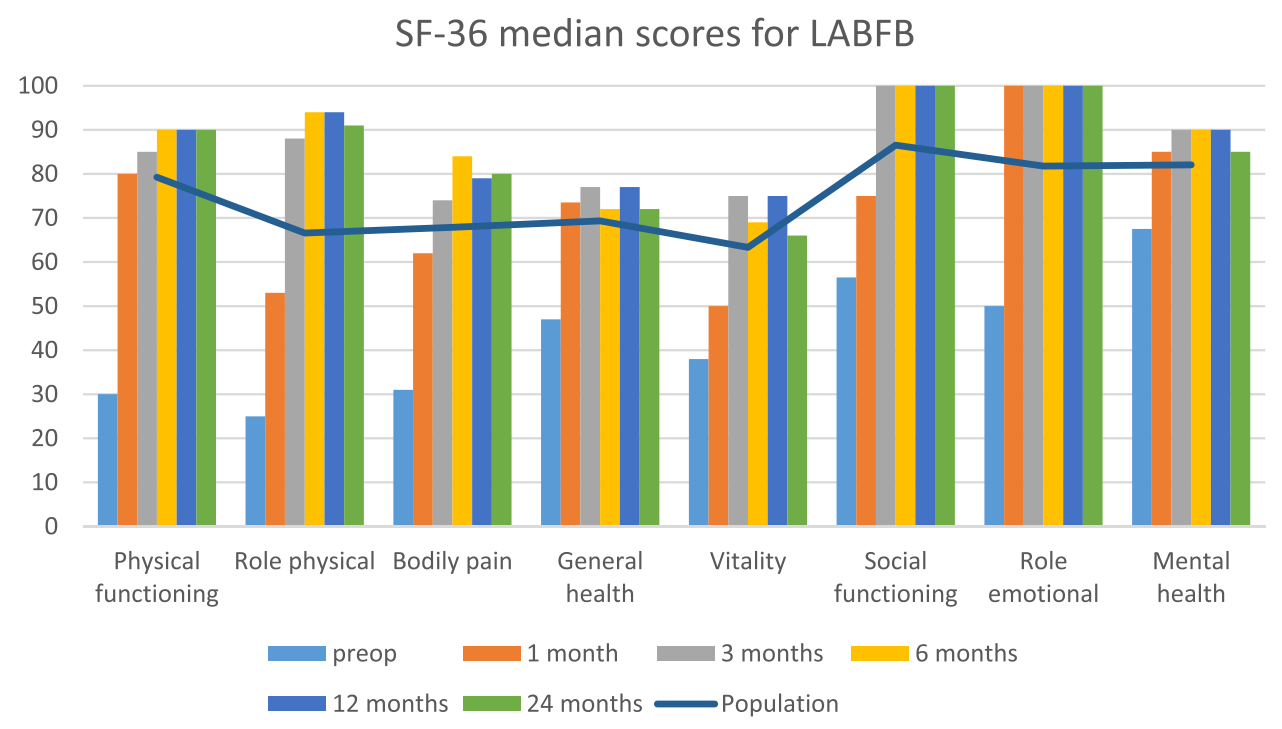

\section{SF-36 median scores for OABFB}

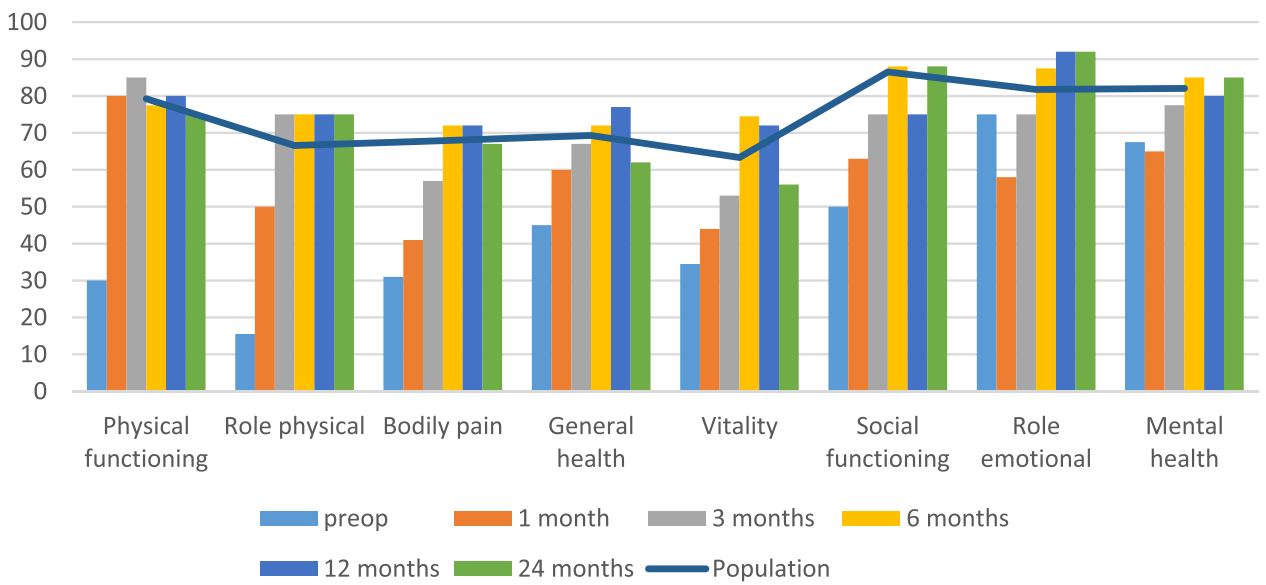

Figure 3 SF-36 median individual domain scores change as compared with the preoperative scores at I, 3, 6, I2 and 24 months postoperatively in 7 I patients randomized to either laparoscopic aortobifemoral bypass (LABFB) or open aortobifemoral bypass (OABFB) for the treatment of aortoiliac occlusive disease, Trans-Atlantic Inter-Society Consensus II, Type D lesions. ${ }^{2}$ (Wilcoxon Signed Ranks Test, for LABFB $p<0.005$ for all time points; for OABFB $p<0.005$ except at I month for VT, SF, MH and RE). Agematched Norwegian population norms for SF-36 domains are also plotted. ${ }^{23}$

the help of EQ-5D. EQ-5D has been a frequently used questionnaire by health economists for performing costeffectiveness analysis. EQ-5D questionnaires are simple, and it takes a shorter time to be answered by the patients. ${ }^{29,30}$

Based on the EQ-5D VAS, the patients in the LABFB had better postoperative general health perception than OABFB patients at 1 and 12 months postoperatively.

Table 5 Longitudinal Comparison of EQ-5D Scores in 7I Patients Randomized to Either Laparoscopic or Open Aortobifemoral Bypass to Treat AIOD, TASC II Type D Lesions. ${ }^{2}$

\begin{tabular}{|l|l|l|l|l|l|l|}
\hline \multirow{2}{*}{ EQ-5D } & Preop. & I Month & $\mathbf{3}$ Months & $\mathbf{6}$ Months & I2 Months & 24 Months \\
\cline { 2 - 7 } & Median (IQR) & Median (IQR) & Median (IQR) & Median (IQR) & Median (IQR) & Median (IQR) \\
\hline LABFB & $0.58(0.42)$ & $0.92(0.11)$ & $0.937(0.15)$ & $0.937(0.09)$ & $1(0.12)$ & $1(0.14)$ \\
OABFB & $0.49(0.31)$ & $0.765(0.18)$ & $0.833(0.16)$ & $0.859(0.17)$ & $0.879(0.19)$ & $0.879(0.19)$ \\
P- value * & 0.911 & $<0.001$ & 0.03 & 0.005 & 0.03 & 0.70 \\
\hline
\end{tabular}

Note: Statistics: Mann-Whitney U-test*.

Abbreviations: IQR, interquartile range; AIOD, aorto-iliac occlusive disease; TASC II, Trans-Atlantic Inter-Society Consensus II; LABFB, laparoscopic aortobifemoral bypass; OABFB, open aortobifemoral bypass; EQ-5D, EuroQol 5 dimensions. 


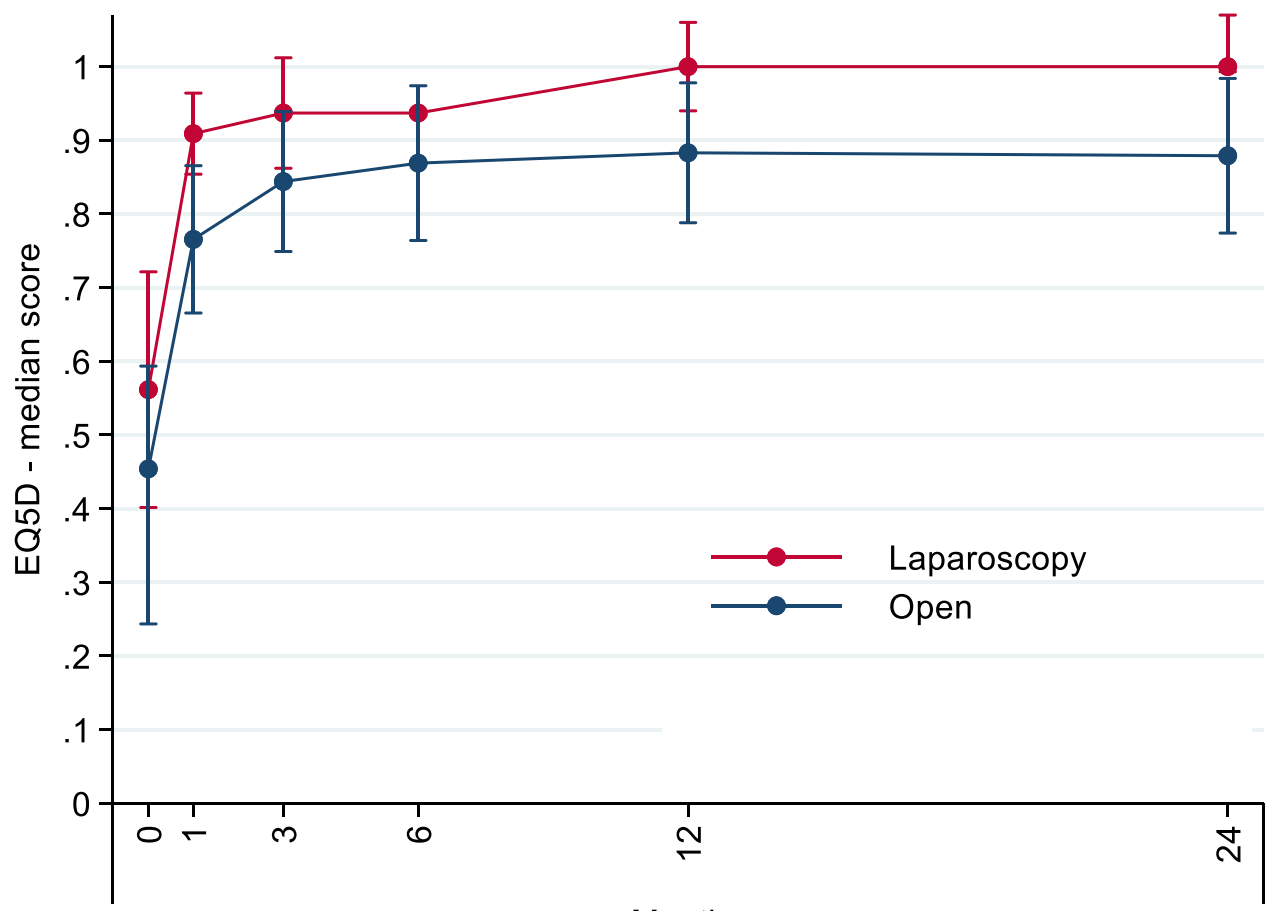

Months

Figure 4 Comparison of EQ-5D median scores preoperatively, and at I, 3, 6, I2, and 24 months after laparoscopic or open aortobifemoral bypass in 7I patients with advanced aortoiliac occlusive disease, TASC II Type D lesions. ${ }^{2}$ Vertical bars represent interquartile range. (Mann-Whitney U-Test: significant $\mathrm{P}$ value at I, 3, 6 and I2 months postoperatively, $<0.001,<0.03,<0.005$ and $<0.03$ respectively, in favor of Laparoscopic operation).

Abbreviations: TASC II, Trans-Atlantic Inter-Society Consensus II; EQ-5D, EuroQol 5 dimensions.

In this study, all three PROMs tools have confirmed a better improvement in the QoL of the patients in the LABFB than OABFB. The study has shown better QoL in the patients after laparoscopic operation at 1 and 3 months postoperatively, assessed with SF-36. However, individual domains and the component scores are significantly better in the laparoscopy group beyond the first two postoperative time-points. QoL assessment results of SF-36 in this study are in accordance with the results of previous publications. ${ }^{31,32}$

Both surgical procedures seem to provide a significant improvement in the QoL of these patients compared with the preoperative QoL. Interestingly, postoperatively, the QoL in both patient groups comes to the general Norwegian population norms level. However, in the case of laparoscopic bypass, the QoL domains after three months' time-point scored higher than the open group and the Norwegian norms. Partly, this can be due to the ceiling effect, which is mainly well known for the PF, RP, BP, Sf, and RE scales. ${ }^{26,33}$ Another factor that could have added to the difference between the groups could be the impact of postoperative complications on the QoL. Although regression analysis performed has not found any statistically significant effect of 30 days complications and hospital stay, complications beyond 30 days have not been included in this analysis. This

Table 6 Comparison of EQ-5D, Visual Analog Scale (VAS) at Different Time-Points in 7I Patients with AIOD, TASC II Type D Lesions, Randomized to Either Laparoscopic or Open Aortobifemoral Bypass Treatment. ${ }^{2}$ EQ-5D VAS Represents the Patient's Perception of His/Her Current Health Status Ranging from 0 to 100, where 100 is the Best Possible Health Status.

\begin{tabular}{|l|l|l|l|l|l|l|}
\hline \multirow{2}{*}{ EQ-5D VAS } & Preoperative & I Month & $\mathbf{3}$ Months & $\mathbf{6}$ Months & I2 Months & 24 Months \\
\cline { 2 - 7 } & Median (IQR) & Median (IQR) & Median (IQR) & Median (IQR) & Median (IQR) & Median (IQR) \\
\hline Laparoscopy & $50(25)$ & $80(15)$ & $85(19)$ & $80(25)$ & $80(24)$ & $80(35)$ \\
Open & $45(20)$ & $62.5(33)$ & $75(33)$ & $70(35)$ & $70(40)$ & $70(25)$ \\
P-value* & 0.143 & 0.005 & 0.065 & 0.7 & 0.037 & 0.137 \\
\hline
\end{tabular}

Note: *Mann-Whitney U-test.

Abbreviations: IQR, interquartile range; EQ-5D VAS, Euroqol 5 dimensions visual analog scale. 
study is a sub-study that was not powered for analyzing the effect of complications on the QoL, and this factor adds to the study limitations. Nevertheless, the strength of our study is its randomized design.

Another limitation of this study is the lack of a disease-specific quality of life questionnaire. No validated diseasespecific questionnaire was available in the Norwegian language at the NLAST trial. VascuQol-6 is a disease-specific questionnaire that was not validated in the Norwegian language until $2017 .{ }^{34}$ However, this disease-specific questionnaire would not necessarily capture the differences in the QoL after major abdominal surgery.

\section{Conclusion}

The patients with AIOD TASC II type D lesions operated with laparoscopic aortobifemoral bypass seem to achieve earlier, better, and sustainable improvement in their postoperative QoL than patients treated with open aortobifemoral bypass.

\section{Data Sharing Statement}

Individual participant data reported in this article, after deidentification, will be made available at the end of the ongoing trial (Norwegian Laparoscopic aortic Surgery Trial) during 2022. Requests for data sharing shall be directed to the prime investigator of the NLAST study, Kazmi, SSH MD, Ph.D., syekaz@ous-hf.no.

\section{Acknowledgments}

We are thankful to Mrs. Ragnhild S Falk at the Oslo Centre for Biostatistics and Epidemiology (OCBE), Oslo University Hospital, Oslo, Norway, and Ms. Anne Schad Bergsaker, at the Department for data capture and collections management, University in Oslo, Oslo, Norway, for their kind assistance for statistical help.

\section{Author Contributions}

All authors made a significant contribution to the work reported, whether that is in the conception, study design, execution, acquisition of data, analysis and interpretation, or in all these areas; took part in drafting, revising or critically reviewing the article; gave final approval of the version to be published; have agreed on the journal to which the article has been submitted; and agreed to be accountable for all aspects of the work.

\section{Disclosure}

Dr Torbjørn Wisløff reports funding for completely unrelated work with varicella and herpes zoster vaccine from MSD. The authors report no other conflicts of interest in this study.

\section{References}

1. Jongkind V, Akkersdijk GJ, Yeung KK, Wisselink W. A systematic review of endovascular treatment of extensive aortoiliac occlusive disease. J Vasc Surg. 2010;52(5):1376-1383. doi:10.1016/j.jvs.2010.04.080

2. Norgren L, Hiatt WR, Dormandy JA, et al. Inter-society consensus for the management of peripheral arterial disease (TASC II). $J$ Vasc Surg. 2007;45:S45-S67. doi:10.1016/j.jvs.2006.12.037

3. Aboyans V, Ricco JB, Bartelink ML, et al. [2017]. ESC Guidelines on the Diagnosis and Treatment of Peripheral Arterial Diseases, in collaboration with the European Society for Vascular Surgery (ESVS)]. Eur Heart J. 2018;39:763-821. doi:10/1093/eurheartj/ehx095

4. Sachwani GR, Hans SS, Khoury MD, et al. Results of iliac stenting and aortofemoral grafting for iliac artery occlusions. J Vasc Surg. 2013;57 (4):1030-1037. doi:10.1016/j.jvs.2012.09.038

5. Ballotta E, Lorenzetti R, Piatto G, Tolin F, Da Giau G, Toniato A. Reconstructive surgery for complex aortoiliac occlusive disease in young adults. J Vasc Surg. 2012;56(6):1606-1614. doi:10.1016/j.jvs.2012.05.105

6. Coggia M, Javerliat I, Di Centa I, et al. Total laparoscopic bypass for aortoiliac occlusive lesions: 93-case experience. J Vasc Surg. 2004;40 (5):899-906. doi:10.1016/j.jvs.2004.08.013

7. Di Centa I, Coggia M, Cerceau P, et al. Total laparoscopic aortobifemoral bypass: short- and middle-term results. Ann Vasc Surg. 2008;22 (2):227-232. doi:10.1016/j.avsg.2007.08.004

8. Kazmi SSH, Jorgensen JJ, Sundhagen JO, et al. A comparative cohort study of totally laparoscopic and open aortobifemoral bypass for the treatment of advanced atherosclerosis. Vasc Health Risk Manag. 2015;11:541-547. doi:10.2147/VHRM.S92671

9. Ismail I, Wolff S, Gronfier A, Mutter D, Swanstrom LL. A cost evaluation methodology for surgical technologies. Surg Endosc. 2015;29 (8):2423-2432. doi:10.1007/s00464-014-3929-4

10. Kind P, Lafata JE, Matuszewski K, Raisch D. The use of QALYs in clinical and patient decision-making: issues and prospects. Value Health. 2009;12(Suppl 1):S27-S30. doi:10.1111/j.1524-4733.2009.00519.x 
11. Mays RJ, Casserly IP, Kohrt WM, et al. assessment of functional status and quality of life in claudication. J Vasc Surg. 2011;53(5):1410-1421. doi:10.1016/j.jvs.2010.11.092

12. Kazmi SSH, Krog AH, Berge ST, Sundhagen JO, Sahba M, Falk RS. Patient-perceived health-related quality of life before and after laparoscopic aortobifemoral bypass. Vasc Health Risk Manag. 2017;13:169-176. doi:10.2147/VHRM.S134669

13. Breek JC, de Vries J, van Heck GL, Van berge Henegouwen DP, Hamming JF. Assessment of disease impact in patients with intermittent claudication: discrepancy between health status and quality of life. J Vasc Surg. 2005;41(3):443-450. doi:10.1016/j.jvs.2004.12.042

14. Hicks CW, Lum YW. Patient-reported outcome measures in vascular surgery. Semin Vasc Surg. 2015;28(2):122-133. doi:10.1053/j. semvascsurg.2015.09.006

15. van Hattum ES, Tangelder MJ, Lawson JA, Moll FL, Algra A. The quality of life in patients after peripheral bypass surgery deteriorates at long-term follow-up. J Vasc Surg. 2011;53(3):643-650. doi:10.1016/j.jvs.2010.09.021

16. Larsen ASF, Reiersen AT, Nådland IH, Wesche J. Self-reported health status and disease-specific quality of life one year after treatment for peripheral arterial disease in clinical practice. Health Qual Life Outcomes. 2020;18:235. doi:10.1186/s12955-020-01477-y

17. Treat-Jacobson D, Lindquist RA, Witt DR, et al. The PADQOL: development and validation of a PAD-specific quality of life questionnaire. Vasc Med. 2012;17(6):405-415. doi:10.1177/1358863X12466708

18. Gomez FP, Rodriguez-Rosin R. Global initiative for chronic obstructive lung disease (GOLD) guidelines for chronic obstructive pulmonary disease. Curr Opin Pulm Med. 2002;8:81-86. doi:10.1097/00063198-200203000-00001

19. Ware JE. SF-36 Health Survey: Manual \& Interpretation Guide. 2nd ed. Lincoln, RI: QualityMetric Inc.; 2000.

20. Brooks R, Rabin R, de Charro F The measurement and valuation of health status using EQ-5D: a European perspective Kluwer Academic, Dordrecht 2003.

21. Ware JE, Gandek B, Kosinski M, et al. The equivalence of SF-36 summary health scores estimated using standard and country-specific algorithms in 10 countries: results from the IQOLA project. J Clin Epidemiol. 1998;51(11):1167-1170. doi:10.1016/S0895-4356(98)00108-5

22. Fontaine R, Kim M, Kieny R. Surgical treatment of peripheral circulation disorders. Helv Chir Acta. 1954;21(5-6):499-533.

23. Garratt AM, Stavem K. Measurement properties and normative data for the Norwegian SF-36: results from a general population survey. Health Qual Life Outcomes. 2017;15(1):51. doi:10.1186/s12955-017-0625-9

24. Vaidya A, Kleinegris M-C, Severens JL, et al. Comparison of EQ-5D and SF-36 in untreated patients with symptoms of intermittent claudication. J Comp Eff Res. 2018;7(6):535-548. doi:10.2217/cer-2017-0029

25. Nylaende M, Abdelnoor M, Stranden E, et al. The Oslo balloon angioplasty versus conservative treatment study (OBACT)-the 2-years results of a single centre, prospective, randomised study in patients with intermittent claudication. Eur J Vasc Endovasc Surg. 2007;33(1):3-12. doi:10.1016/j. ejvs.2006.08.007

26. Jacobsen EL, Bye A, Aass N, et al. Norwegian reference values for the short-form health survey 36: development over time. Qual Life Res. 2018;27:1201-1212. doi:10.1007/s11136-017-1684-4

27. Spronk S, White JV, Bosch JL, Hunink MG. Impact of claudication and its treatment on quality of life. Semin Vasc Surg. 2007;20(1):3-9. doi:10.1053/j.semvascsurg.2007.02.003

28. Donker J, de Vries J, Ho GH, et al. Review: quality of life in lower limb peripheral vascular surgery. Vascular. 2016;24(1):88-95. doi:10.1177/ 1708538115578961

29. Djerf H, Svensson M, Nordanstig J, Gottsäter A, Falkenberg M, Lindgren H. Cost-effectiveness of primary stenting in the superficial femoral artery for intermittent claudication: two year results of a randomised multicentre trial. Eur J Vasc Endovasc Surg. 2021;62(4):576-582. doi:10.1016/j. ejvs.2021.07.009

30. Krog AH, Sahba M, Pettersen EM, Wisloff T, Sundhagen JO, Kazmi SS. Cost-utility analysis comparing laparoscopic vs. open aortobifemoral bypass surgery. Vasc Health Risk Manag. 2017;13:217-224. doi:10.2147/VHRM.S138516

31. Toritani K, Watanabe J, Nakagawa K, et al. Randomized controlled trial to evaluate laparoscopic versus open surgery in transverse and descending colon cancer patients. Int J Colorectal Dis. 2019;34:1211-1220. doi:10.1007/s00384-019-03305-2

32. Theodoropoulos GE, Karantanos T. Quality of life after laparoscopic colectomy for cancer. JSLS. 2014;18:225-235. doi:10.4293/ 108680813X13753907291152

33. Austin PC. Bayesian extensions of the Tobit model for analyzing measures of health status. Med Decis Making. 2002;22(2):152-162. doi:10.1177/ 0272989X0202200212

34. Larsen ASF, Reiersen AT, Jacobsen MB, et al. Validation of the Vascular quality of life questionnaire - 6 for clinical use in patients with lower limb peripheral arterial disease. Health Qual Life Outcomes. 2017;15(1):184. doi:10.1186/s12955-017-0760-3

Vascular Health and Risk Management

Dovepress

\section{Publish your work in this journal}

Vascular Health and Risk Management is an international, peer-reviewed journal of therapeutics and risk management, focusing on concise rapid reporting of clinical studies on the processes involved in the maintenance of vascular health; the monitoring, prevention and treatment of vascular disease and its sequelae; and the involvement of metabolic disorders, particularly diabetes. This journal is indexed on PubMed Central and MedLine. The manuscript management system is completely online and includes a very quick and fair peer-review system, which is all easy to use. Visit http://www.dovepress.com/testimonials.php to read real quotes from published authors.

Submit your manuscript here: https://www.dovepress.com/vascular-health-and-risk-management-journal 